\title{
Salivary 8-hydroxyguanosine levels in smokers and non-smokers with chronic periodontitis
}

\author{
Varghese, Jothi ; Bhat, Vinutha ; Chianeh, Yousef Rezaei ; Kamath, V ; Al-Haj Husain, Nadin ; Özcan, Mutlu
}

\begin{abstract}
This case-controlled clinical trial was performed on the salivary 8-hydroxyguanosine (8-OHdG) levels in smokers and non-smokers with chronic periodontitis after non-surgical periodontal therapy. Subjects $(\mathrm{N}=$ 40) with periodontitis (smokers and non-smokers) and with clinically healthy conditions (smokers and nonsmokers) were assigned to this study. At baseline, clinical periodontal parameters (plaque index, gingival index, pocket probing depth and clinical attachment levels) were evaluated. Saliva samples were obtained pre- and posttreatment to quantify the 8-OHdG levels using Elisa technique. Subjects diagnosed with chronic periodontitis with smoking habit (CPs) and non-smokers (CPns) received scaling and root planing. In clinically healthy subjects with smoking habit $(\mathrm{CHs})$ and non-smokers $(\mathrm{CHns})$, only oral hygiene tutoring was performed. All clinical measurements and salivary collection were repeated in a 3-month recall interval. Data were analyzed using Anova, Tukey post hoc test and Mann-Whitney 'U' tests $(\mathrm{P}<0.05)$. At baseline, CPs and CPns groups showed significantly higher PI, GI, PD and CAL values than those of $\mathrm{CHns}$ and $\mathrm{CHs}(\mathrm{P}<0.001)$. Baseline salivary levels of 8-OHdG were significantly higher in CPs group $(14.775 \mathrm{pg} / \mathrm{mL})(\mathrm{P}<0.001)$ compared to the other groups. All clinical parameters in chronic periodontitis group improved at the 3rd month recall interval, however, with regards to 8-OHdG values, the $\mathrm{CP}$ smoker category still had a higher level compared to $\mathrm{CP}$ non-smoker. This study reflects an on-going periodontal destructive status in smokers and salivary 8-OHdG levels could be recognized as an oxidative biomarker for determining periodontal tissue destruction.
\end{abstract}

DOI: https://doi.org/10.1007/s10266-020-00496-x

Posted at the Zurich Open Repository and Archive, University of Zurich

ZORA URL: https://doi.org/10.5167/uzh-197808

Journal Article

Accepted Version

Originally published at:

Varghese, Jothi; Bhat, Vinutha; Chianeh, Yousef Rezaei; Kamath, V; Al-Haj Husain, Nadin; Özcan, Mutlu (2020). Salivary 8-hydroxyguanosine levels in smokers and non-smokers with chronic periodontitis. Odontology / the Society of the Nippon Dental University, 108(4):569-577.

DOI: https://doi.org/10.1007/s10266-020-00496-x 


\section{Salivary 8-Hydroxyguanosine Levels In Smokers and Non-Smokers With Chronic}

\section{Periodontitis}

\section{Jothi Varghese • Vinutha Bhat • Yousef Rezaei Chianeh • Kamath V}

\section{- Nadin Al-Haj Husain • Mutlu Özcan}

Jothi Varghese

Manipal University, Department of Periodontology, Manipal College of Dental Sciences, Manipal Academy of Higher Education, Manipal, India

Vinutha Bhat

Manipal University, Department of Biochemistry, Kasturba Medical College, Manipal Academy of Higher Education, Manipal, India

Yousef Rezaei Chianeh

Manipal University, Department of Biochemistry, Kasturba Nedical College, Manipal Academy of Higher Education, Manipal, India

\section{Kamath V}

Department of Public health dentistry, Goa Dental College and Hospital, Bambolim, Goa, India

Nadin Al-Haj Husain

University of Bern, School of Dental Medicine, Department of Reconstructive Dentistry and Gerodontology, Bern, Switzerland

Mutlu Özcan (D)

University of Zürich, Dental Materials Unit, Center for Dental and Oral Medicine Clinic for Fixed and Removable Prosthodontics and Dental Materials Science, Zürich, Switzerland

Short title: 8-Hydroxyguanosine levels in smokers and non-smokers with chronic periodontitis

\section{Corresponding to:}

Prof. Dr. Mutlu Özcan, Ph.D

University of Zurich

Center for Dental and Oral Medicine

Dental Materials Unit

Clinic for Fixed and Removable Prosthodontics

and Dental Materials Science

Plattenstrasse 11, $\mathrm{CH}-8032$

Zurich, Switzerland

Tel: +41 446345600

e-mail: mutluozcan@hotmail.com 
Abstract: The purpose of this case controlled clinical trial is to study the salivary 8Hydroxyguanosine (8-OHdG) levels in smokers and non-smokers with chronic periodontitis after non-surgical periodontal therapy. Subjects $(\mathrm{N}=40)$ with periodontitis (smokers and non-smokers) and with clinically healthy conditions (smokers and non-smokers) were assigned to this study. At baseline, clinical periodontal parameters (plaque index, gingival index, pocket probing depth and clinical attachment levels) were evaluated. Saliva samples were obtained pre and post treatment in order to quantify the 8-Hydroxyguanosine (8-OHdG) levels. Subjects diagnosed with chronic periodontitis with smoking habit (CPs) and non-smokers (CPns) received scaling and root planing (SRP). In clinically healthy subjects with smoking habit $(\mathrm{CHs})$ and non-smokers (CHns), only scaling and oral hygiene tutoring were performed. All clinical measurements and salivary collection were repeated in a 3 month recall interval. $8-\mathrm{OHdG}$ levels were measured using a competitive enzyme immunoassay technique. Data were analyzed using Anova, Tukey post hoc test and Mann Whitney ' $\mathrm{U}$ ' tests (alpha=0.05). At baseline, CPs and CPns groups showed significantly higher PI, GI, PD and CAL values than those of $\mathrm{CHns}$ and $\mathrm{CHs}(P<0.001)$. Baseline salivary levels of 8OHdG were significantly higher in CPs group $(14.775 \mathrm{pg} / \mathrm{mL})(P<0.001)$ compared to the other groups. All clinical parameters in chronic periodontitis group improved at the $3^{\text {rd }}$ month recall interval, however with regards to $8-\mathrm{OHdG}$ values, the $\mathrm{CP}$ smoker category still had a higher level compared to $\mathrm{CP}$ non smoker .Hence, reflecting an on-going periodontal destructive status. The results of this study exhibits salivary $8-\mathrm{OHdG}$ levels could be recognized as an oxidative biomarker for determining periodontal tissue destruction.

Keywords: 8-Hydroxyguanosine • Chronic Periodontitis • Salivary biomarker • Smoking Oxidative stress 


\section{Introduction}

Periodontitis is an inflammatory disorder wherein complex interactions between the microorganisms, host response mechanisms and environmental factors result in tissue damage. Among the environmental factors, smoking has been linked with increased morbidity and mortality. Over the last decade, there have been a number of reviews that have considered the biological mechanisms underlying susceptibility of smokers to periodontitis in $[1,2]$. As per demographic records, smokers demonstrate a 2.6 to 6 fold increased incidence of periodontitis compared to non-smokers [3] and decreased response to periodontal therapy $[4,5]$.

Despite the fact that a clear dose-response relationship between chronic periodontitis and smoking was reported [6], the mechanisms by which smoking contributes to the pathogenesis of periodontitis are not yet clearly understood. However, smokers are more likely to harbour a higher prevalence of potential periodontal pathogens, which could influence host-cytokine levels $[7,8]$.

The past few decades have gathered strong evidence which implicates oxidative stress in the pathogenesis of periodontal disease [9,10]. Free radicals and reactive oxygen species (ROS) at normal levels are essential for normal biological processes [11] that could also have deleterious effects at higher concentrations leading to oxidative damage. Generally, the homeostatic balance between ROS and free radicals are disturbed by various factors one which is smoking that may enhance oxidative stress not only through the production of reactive oxygen radicals in smoke but also through weakening of the antioxidant defence systems [12,13]. ROS and in particular the 
active hydroxyl $(\mathrm{OH})$ group radical, are known to be involved in the destruction of various functional macromolecules, like free and conjugated proteins, lipids and carbohydrates eventually resulting in cellular damage $[14,15]$. Polymorphonuclear leukocytes (PMN) are the initial defence cells that predominantly encircles the area accumulated by bacterial pathogens in pathological conditions including periodontitis. Such an infiltration in numbers is likely to lead to an increase in ROS levels [16].

8-Hydroxyguanosine (8-OHdG) is an oxidized nucleoside that is excreted in the body fluids as a reparative consequence of DNA. A stable product that is formed as a result of enzymatic dissolution after ROS induces 8-hydroxylation of guanine base on mitochondrial and nuclear DNA $[17,18]$. Studies have demonstrated that the $8-\mathrm{OHdG}$ released in body fluids and tissues has been implicated in the pathogenesis of malignancy, inflammatory, autoimmune disorders and diabetes mellitus $[19,20]$.

A correlation between the salivary levels of $8-\mathrm{OHdG}$ and periodontal microbiota has been reported indicating its effectiveness as a supportive biomarker for determination of periodontal status $[21,22]$. Furthermore, a recent clinical investigation has revealed that initial periodontal therapy has a beneficial effect on decreasing the substantial levels of oxidative biomarkers in smokers and non-smokers [23], thus validating its use as a signature molecule in diagnosis. However, the association between smoking and its effect on diseased periodontium at a cellular level still remains uncertain.

The primary objectives of this study therefore were to estimate the salivary levels of $8-\mathrm{OHdG}$ in smokers and non-smokers with chronic periodontitis and also to determine its level after initial periodontal therapy. 


\section{Materials and methods}

\section{Study groups}

The present case controlled clinical trial with an intervention arm, involved a total of 40 subjects ( $n=10$ per group), comprising of group $1=$ smokers with chronic periodontitis (CPs), group 2=nonsmokers with chronic periodontitis (CPns), group $3=$ clinically healthy smokers $(\mathrm{CHs})$ and group $4=$ non-smokers with clinically healthy periodontium (CHns). Ethical approval was obtained from the institutional review board. All participants were informed regarding the study and a written informed consent was obtained on voluntary participation. Subjects were excluded if they had any systemic disease/immune-compromised condition, or recent history of intake of antibiotics, antiinflammatory and anti-oxidants and dietary supplements.

Diagnosis for chronic periodontitis was based on the 1999 international world workshop for classification of periodontal diseases and conditions [24]. A clinical and radiographic assessment characterized recruitment of chronic periodontitis patients by at least $30 \%$ teeth with pockets $>5$ $\mathrm{mm}$. Smokers were categorized based on verbal query of $\geq 10$ cigarettes/day for more than 5 years. Non-smoker groups were subjects who fulfilled the norms of not having smoked cigarettes in their lifetime. The healthy group of individuals were categorized based on systemic well-being, having teeth with pocket depth $\leq 3 \mathrm{~mm}$, no attachment loss, no bleeding on gentle probing and with radiographic confirmation of no bone loss.

\section{Clinical measurements and initial periodontal therapy}

Only subjects who fulfilled the inclusion criteria were incorporated into the clinical trial. All clinical measurements were performed by a single examiner. Initially, $5 \mathrm{ml}$ of unstimulated whole saliva samples were obtained in Eppendorf tubes [25] prior to clinical examination in order to avoid any contamination of the oral fluids which could deter the results. Then, basic periodontal parameters 
comprising of Plaque index (PI) [26], Gingival Index (GI) [27], Probing pocket depth (PPD) and Clinical attachment level (CAL) were recorded on a standard form. PD and CAL were assessed on six sites of a tooth where the deepest probing depth was recorded using William's periodontal probe. Subsequently, all patients received scaling and root planing (SRP), which were completed in at least 2 appointments. As per the routine norm, oral hygiene instructions were given to all subjects. In clinically healthy smoker and non-smoker category, only scaling and oral hygiene tutoring were performed. All clinical measurements and salivary collection were repeated in the 3 month recall interval. The collected saliva samples were centrifuged $(2.000 \mathrm{~g}$ for $10 \mathrm{~min})$ and the supernatants were stored at $-80^{\circ} \mathrm{C}$ until they were assayed.

\section{Detection of $80 \mathrm{OHG}$}

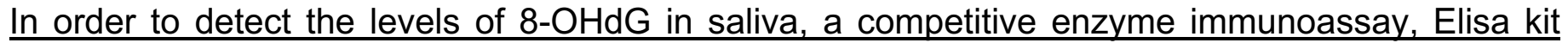
(Cloud-Clone Corp, Houston, Texas, USA) was used according to the manufacturer's instructions. The detection range was $74.07-6000 \mathrm{pg} / \mathrm{mL}$.

\section{Statistical analysis}

The data collected was entered into microsoft excel spreadsheet and analyzed using IBM SPSS Statistics, Version 22(Armonk, NY: IBM Corp). Descriptive data were presented in the form of mean, median, standard deviation and quartiles. Based on the distribution of the data, parametric or non parametric tests were used. Comparison of the study variables at baseline was done using ANOVA with Tukey post hoc test. Post treatment statistical data was analyzed by Independent sample $t$ test. Paired $t$ test was used compare the study variables between baseline and post treatment. Mann Whitney ' $U$ ' test was used to compare the change in the clinical parameters and 8 OHdG levels for chronic periodontitis (CP and CP smokers) post periodontal therapy. Pearson's 
and Spearman's correlation test was used to test the correlation between the study variables and 8-OHdG. P value less than 0.05 were considered to be statistically significant in all tests.

\section{Results}

All patients involved in this clinical trial returned for the follow-up visits. With regards to gender distribution, only males had volunteered to participate. The age of subjects with chronic periodontitis (smokers and non-smokers) were 40-65 years while the age of the healthy controls were between 25 and 35 years.

\section{Baseline clinical findings}

At baseline, chronic periodontitis (smoker and non-smoker) group presented significantly higher values of PI, GI, PD and CAL compared to clinically healthy (smoker and non-smoker) group $(P<0.001)($ Table 1a). The salivary levels of $8-O H d G$ exhibited significantly higher levels in $C P$ smokers group $(14.775 \mathrm{pg} / \mathrm{mL}) \quad(P<0.001)$ compared to the other test groups (Table 1a). Comparison of clinical variables between the groups at baseline revealed, notable statistical significance in all groups, except in PI values in the clinically healthy smokers and non smokers and the PPD and CAL values between the chronic periodontitis and clinically healthy smokers and non-smokers (Table 1b).

\section{Post treatment (3-month) recall period.}

Initial periodontal therapy was provided only for CP (smoker and non-smoker) group. The other two groups belonged to the healthy category and hence only oral health measures were instructed. All clinical parameters demonstrated reduction in measurements at the 3rd month recall interval (Table 2). Considering comparisons between groups $1 \& 2$, the PI ranges did display reduction but were not statistically significant among the groups .However, the CP non-smoker category display 
marked significant reduction in $\mathrm{GI}$ values compared to $\mathrm{CP}$ smoker category $(\mathrm{P}<0.001)$. Likewise, the post treatment 8 OHdG levels were seen to reduce in both groups, with predisposition in the CP non smoker group $(\mathrm{P}<0.001)$ (Table 2$)$.

\section{Baseline-post periodontal therapy comparison}

Intergroup comparison within CP groups demonstrated significant reduction in all parameters , except in PPD levels in CP non-smokers category (Table 3). Notable changes were examined in the variables during the study period between the CP groups using the Mann Whitney $U$ test, which showed all significant figures except in variables of CAL and $8 \mathrm{OHdG}$, wherein no statistical changes were observed (Table 4).

\section{Correlation between $80 \mathrm{HdG}$ levels and clinical variables}

A positive correlation was observed post treatment between $8 \mathrm{OHdG}$ and PPD levels in Group 2 $(r=0.63)$, which exhibited a statistical significant effect $(p=0.04)$ (Table 5)

\section{Discussion}

The present clinical trial has been conducted to relate the relevance of oxidative damage induced by ROS that are liberated during periodontal disease process and the damage caused by the influence of smoking on the periodontium. For this purpose, 8-OHdG was chosen as a biomarker for estimation of oxidative DNA damage. The deleterious effects of oxidative stress generally follows after exposure to a high concentration of ROS and/or inadequate functioning of antioxidant defence system within the host. Lately, this has been linked to various systemic diseases including periodontitis $[9,23]$. 
In this study, at baseline clinical parameters (PI, GI, PD and CAL) of the chronic periodontitis group (smokers and non-smokers) showed higher values compared to the healthy category (smokers and non-smokers) which validates the periodontal disease process. Saliva is a naturally available biofluid that can be collected with ease from the patient without any need of sophisticated tool. It contains various constituents which reflects the relationship between periodontal disease and diseases of other systemic tissues/organs. Literature review have revealed that unstimulated saliva contains some GCF elements and tissue metabolites which are beneficial for estimation of periodontal disease $[28,29]$. In advanced periodontal disease with hopeless prognosis, salivary $8 \mathrm{OHdG}$ levels were found to be high, suggesting its role as a biomarker $[22,30,31]$. In this present study, the levels of $8-O H d G$ in saliva were significantly higher in the chronic periodontitis and smoker groups compared to clinically healthy category. Similar results were observed previously where higher levels of this oxidative biomarker were correlated to the clinical parameters [31]. The findings in this study also supported its useful role as an oxidative indicator. In comparison, in the smokers category (chronic periodontitis smokers and clinically healthy smokers) higher mean values of $8-\mathrm{OHdG}$ were observed. This could be explained by the fact that cigarette smoke contains large quantities of ROS [32] and 8-OHdG, being the main by-product of hydroxyl radical attack on DNA that could be regarded as a dependable biomarker for oxidative damage since it can be ascertained with high sensitivity [33].

Long term exposure to cigarette smoke was reported to increase ROS levels, which in turn decrease the antioxidant status and hindered the DNA restorative capacity that finally led to oxidative DNA damage. Hence, this mechanism led to determining 8-OHdG levels in monitoring oxidative damage in smokers [34].

Salivary flow rate is another factor, found to increase with periodontitis [35], which could be causal for the higher levels of $8-\mathrm{OHdG}$ levels in CP subjects. However, literature related to long term 
effects of smoking shows hypofunction of the salivary glands and hence decreased quantity and quality of salivary flow rate $[36,37]$. However, our findings indicated higher levels of $8-O H D G$ levels in chronic periodontitis and smokers category, reflecting the 8-OHDG as a convincible biomarker of inflammatory destruction. Additionally, age criteria is also a factor that needs to be considered while quantifying this biomarker. A study conducted by Gan W et al [38] observed an agedependant rise in the levels of 8-OHdG marker levels over a wide age group. Since the age group of CP patients in the current study, belonged to $40-65$ years, it could have influenced the higher range of the biomarker. However, the high range of $8 \mathrm{OHdG}$ marker in the healthy smoker category (age range 25-35 years) is perhaps the reflection of inflammatory destruction.

After initial periodontal therapy, all clinical parameters and salivary 8-OHdG levels decreased, which was in accordance with a previous study where significant decrease in 8-OHdG levels both in saliva and GCF were observed [23]. However, work carried out by Dede et al [39] did not comply with the present results, as the authors did not observe a decrease in salivary levels. Also, the present study showed a reduction in biomarker levels in CP non-smokers group after treatment compared to the CP smoker category at the 3rd month recall. This could be attributed to the combined effect of periodontal destruction enhanced by smoking in the CP smokers group. Literature has provided evidence that smokers tend to respond less favourable to periodontal therapy $[4,40,41]$.

Considering the GI values, CP non-smokers demonstrated considerable reduction after SRP compared to CP smokers category. This was supported by the study conducted by Ah et al [4], in which the GI scores in non-smokers were decreased after initial therapy compared to smoker group. This was explained by the decrease in wound healing process in smokers.

Considering the comparison of clinical variables from baseline to $3^{\text {rd }}$ month recall visits, demonstrated significant reduction in both CP groups, except for the PPD levels in CP non- 
smoker group. This state cannot be mitigated with conventional periodontal therapy alone and may require further surgical intervention for pocket elimination.

With regards to changes in the variables during the study interval, almost all parameters demonstrated significant reduction, except for the clinical attachment levels. This was in agreement with previous studies $[42,43]$ wherein the authors have suggested the possibility of a local effect of cigarette and the high serum cotinine levels to be among the reasons for clinical attachment loss. Likewise, post therapeutic difference in $\quad$ 8-OHdG biomarker levels between the two CP groups were also not statistically significant, reflecting that further invasive treatment may be required for complete healing of tissues.

The 3rd month recall interval was chosen according to the plaque control protocol described by Axelsson and Lindhe [44], which was found to be effective against recurrence of periodontitis. The clinically healthy smokers who were acquainted with the smoking habit for at least 5 year period, did not have any periodontal disease. In this study, PI scores in periodontally healthy smokers were comparatively less than the CP groups, which justifies that, well maintained oral health and host response are responsible for disease predisposition.

In the present study, voluntary participation of both genders were intended to be recruited but no female participants joined the trial. This could probably be due to the social stigma of revealing the smoking status. The community where the study was conducted, does not completely accept habitual smoking in woman. Hence, only males were observed to be under the participant category. Future studies should also consider gender effect on the obtained results. 


\section{Conclusions}

The results of the current study suggest that salivary $8-\mathrm{OHdG}$ values can be utilized as an oxidative biomarker for determining periodontal tissue destruction. However, it may not serve as a beneficial determinant to quantify the periodontal destruction occurring in chronic periodontitis smokers and non-smokers category.

\section{Conflict of Interest}

The authors declare that they have no conflict of interest.

\section{References}

1. Preber $\mathrm{H}$, Bergström $\mathrm{J}$. The effect of non-surgical treatment on periodontal pockets in smokers and non-smokers. J Clin Periodontol. 1986;13:319-23.

2. Grossi SG, Skrepcinski FB, DeCaro T, Zambon JJ,Cummins D, Genco RJ. Response to periodontal therapy in diabetics and smokers. J Periodontol. 1996;67:1094-102.

3. Tobacco use and periodontal patients research. Position paper. Sci Ther Comm Amer Academ Periodont. 1999;70:1419-27.

4. Ah MK, Johnson GK, KaldahI WB, Patil KD, Kalkwarf KL. The effect of smoking on the response to periodontal therapy. J Clin Periodont. 1994;21:91-7.

5. Guentsch A, Preshaw PM, Bremer-Streck S, Klinger G, Glockmann E, Sigusch BW. Lipid peroxidation and antioxidant activity in saliva of periodontitis patients; effect of smoking and periodontal treatment. Clin Oral Invest 2008;12:345-52. 
6. Martinez-Canut P, Lorca A, Magan R. Smoking and periodontal disease severity. J Clin Periodontol. 1995; 22:743-9.

7. Tappia PS, Troughton KL, Langley-Evans SC, Grimble RF. Cigarette smoking influences cytokine production and antioxidant defences. Clin Sci. 1995;88:485-9.

8. Boströsm L, Linder LE, Bergström J. Smoking and crevicular fluid levels of IL-6 and TNF- $\alpha$ in periodontal disease. J Clin Periodontol. 1999;26:352-7.

9. Chapple IL, Matthews JB. The role of reactive oxygen and anti-oxidant species in periodontal tissue destruction. Periodontol 2000. 2007;43:160-232.

10. Sulaiman AE, Shehadeh RM. Assessment of total anti-oxidant capacity and the use of vitamin C in the treatment of non-smokers with chronic periodontitis. J Periodont. 2010;81:1547-54.

11. Battino $M$, Bullon $P$, Willson $M$, Newman $H$. Oxidative injury and inflammatory periodontal diseases: the challenge of anti-oxidants to free radicals and reactive oxygen species. Crit Review Oral Bio Med. 1999;10:458-76.

12. Chapple IN. Reactive oxygen species and antioxidants in inflammatory diseases. J Clin Periodontol. 1997;24:287-96.

13. Ryder MI, Fujitaki R, Johnson G, Hyun W. Alterations of neutrophil oxidative burst by invitro smoke exposure: implications for oral and systemic diseases. Annals Periodontol. 1998;3:76-87.

14. Halliwell B. Superoxide-dependent formation of hydroxyl radicals in the presence of iron salts: it's role in the degradation of hyaluronic acid by a superoxide-generating system. FEBS Letts. 1978;96:238-42.

15. Halliwell B, Gutteridge JMC. Lipid peroxidation, oxygen radicals, cell damage and antioxidant therapy. Lancet. 1984;1:1396-8.

16. Miller DR, Lamster IB, Chasens Al. Role of the polymorphonuclear leukocyte in periodontal health and disease. J Clin Periodontol. 1984;11:1-15. 
17. Shigenaga MK, Gimeno CJ, Ames BN. Urinary 8-hydroxy-20-deoxyguanosine as a biological marker of in vivo oxidative DNA damage. Proc Natl Acad Sci USA. 1989;86:9697-701.

18. Cheng KC, Cahill DS, Kasai H, Nishimura S. 8-Hydroxyguanine, an abundant form of oxidative DNA damage, causes GT and AC substitutions. J Biol Chem. 1992;267:166-72.

19. Wu LL, Chiou CC, Chang PY, Wu JT. Urinary 8-0HdG: a marker of oxidative stress to DNA and a risk factor for cancer, atherosclerosis and diabetics. Clin Chem Acta. 2004;339:1-9.

20. Arana C, Cutando A, Ferrera MJ, Gomez-Moreno G, Worf CV, Bolanos MJ, Escames G, Cuna-Castroviejo D. Parameters of oxidative stress in saliva from diabetic and parenteral drug addicts patients. J Oral Pathol Med. 2006;35:554-9.

21. Sawamoto $\mathrm{Y}$, Sugano N, Tanaka H, Ito K. Detection of periodontopathic bacteria and an oxidative stress marker in saliva from periodontitis patients. Oral Microbiol Immunol. 2005;20:21620.

22. Takane M, Sugano N, Iwaski H, Uchiyama T, Ito K. A marker of oxidative stress in saliva: association with periodontally-involved teeth of a hopeless prognosis. J Oral Sci. 2005;47:53-7.

23. Hendek MK, Erdemir EO, Kisa U, Ozcan G. Effect of initial periodontal therapy on the oxidative stress markers in Gingival crevicular fluid, Saliva and serum in smokers and non-smokers with chronic periodontitis. J Periodontol. 2015;86:273-82.

24. Armitage GC. Development of a classification system for periodontal diseases and conditions. Ann Periodontol. 1999;4:1-6.

25. Navazesh M. Methods for collecting saliva. Ann N Y Acad Sci.1993;694:72-7.

26. Silness T, Loë H. Periodontal disease in pregnancy II. Correlation between oral hygiene and periodontal condition. Acta Odontol Scand. 1964;22:121-35.

27. Loë H, Silness T. Periodontal disease in pregnancy I. Prevalence and severity. Acta Odontol Scand. 1963; 21:533-51. 
28. Kaufman E, Lamster IB. Analysis of saliva for periodontal diagnosis-a review. J Clin Periodontol. 2000;27:453-65.

29. Sculley DV, Langley-Evans SC. Salivary antioxidants and periodontal disease status. Proc Nutr Soc. 2002;61:137-43.

30. Su H, Gornitsky M, Velly AM, Yu H, Benarroch M, Schipper HM. Salivary DNA, lipid, and protein oxidation in nonsmokers with periodontal disease. Free Radic Biol Med. 2009;46:914-21.

31. Arunachalam R, Arunima R, Rajeev V, Kurra S, Prince MR, Syam N. Salivary 8hydroxydeoxyguanosine-a valuable indicator for oxidative dna damage in periodontal disease. Saudi J Dent Res. 2015;6:15-20.

32. Church DF, Pryor WA. Free-radical chemistry of cigarette smoke and its toxicological implications. Environ Health Perspect. 1985;64:111-26.

33. Honda M, Yamada Y, Tomonaga M, Ichinose H, Kamihira S. Correlation of urinary 8-hydroxy2'-deoxyguanosine (8-OHdG), a biomarker of oxidative DNA damage, and clinical features of hematological disorders: a pilot study. Leuk Res. 2000;24:461-8.

34. Zhihai C, Dapeng W, Xing L, Weiwei P, Li J, Cao Y, Zhang J, An Y, Nie J, Tong J. Oxidative DNA damage is involved in cigarette smoke-induced lung injury in rats. Environ Health Prev Med. 2015;20:318-24.

35. Mbabali M, Mulli TK and Wagaiyu E. Salivary flow rate in adult Kenyans and its relationship with chronic periodontitis. JDOH 2016; 8(7): 37-42.

36. Petrušić N, Posavac M, Sabol I and Mravak-Stipetić M. The Effect of Tobacco Smoking on Salivation. Acta Stomatol Croat. 2015 ; 49(4): 309-315.

37. Rad M , Kakoie S, Brojeni FN, Pourdamghan N. Effect of Long-term Smoking on Wholemouth Salivary Flow Rate and Oral Health.J Dent Res Dent Clin Dent Prospects. 2010; 4(4): 110_ 114. 
38. Gan W, Liu XL, Yu T, Zou YG, Li TT, Wang S, Deng J, Wang LL, Cai JP. Urinary 8-oxo-7,8dihydroguanosine as a Potential Biomarker of Aging. Front Aging Neurosci $2018 ; 27 ; 10: 34$.

39.Dede FO, Ozden FO, Avcı B. 8-hydroxy-deoxyguanosine levels in gingival crevicular fluid and saliva in patients with chronic periodontitis after initial periodontal treatment. J Periodontol. 2013;84:821-8.

40. Boström L, Linder LE, Bergstrom J. Influence of smoking on the outcome of periodontal surgery. A 5-year follow-up. J Clin Periodontol 1998;25:194-201.

41. Renvert S, Dahlen G, Wikström M. The clinical and microbiological effects of non-surgical periodontal therapy in smokers and non-smokers. J Clin Periodontol. 1998;25:153-7.

42. Linden GJ, Mullally BH. Cigarette smoking and periodontal destruction in young adults. J Periodontol 1994;65:718-23.

43. Haffajee AD, Socransky SS. Relationship of cigarette smoking to attachment level profiles. J Clin Periodontol. 2001;28:283-95.

44. Axelsson P, Lindhe J. Effect of controlled oral hygiene procedures on caries and periodontal disease in adults. J Clin Periodontol. 1978;5:133. 


\section{Captions to legends:}

Table 1a:- Comparison of the variables between the study groups at baseline

Table 1b:- Pairwise comparison of the variables between the study groups at baseline

Table 2:- Comparison of the variables between the study groups at post treatment

Table 3:- Comparison of the variables between baseline and post treatment in chronic periodontitis groups

Table 4:-Comparison of change in the variables during study period between chronic periodontitis groups

Table 5:- Correlation between post treatment $8 \mathrm{OHdG}$ levels and chronic periodontitis smoker and non-smoker group. 
Table 1a

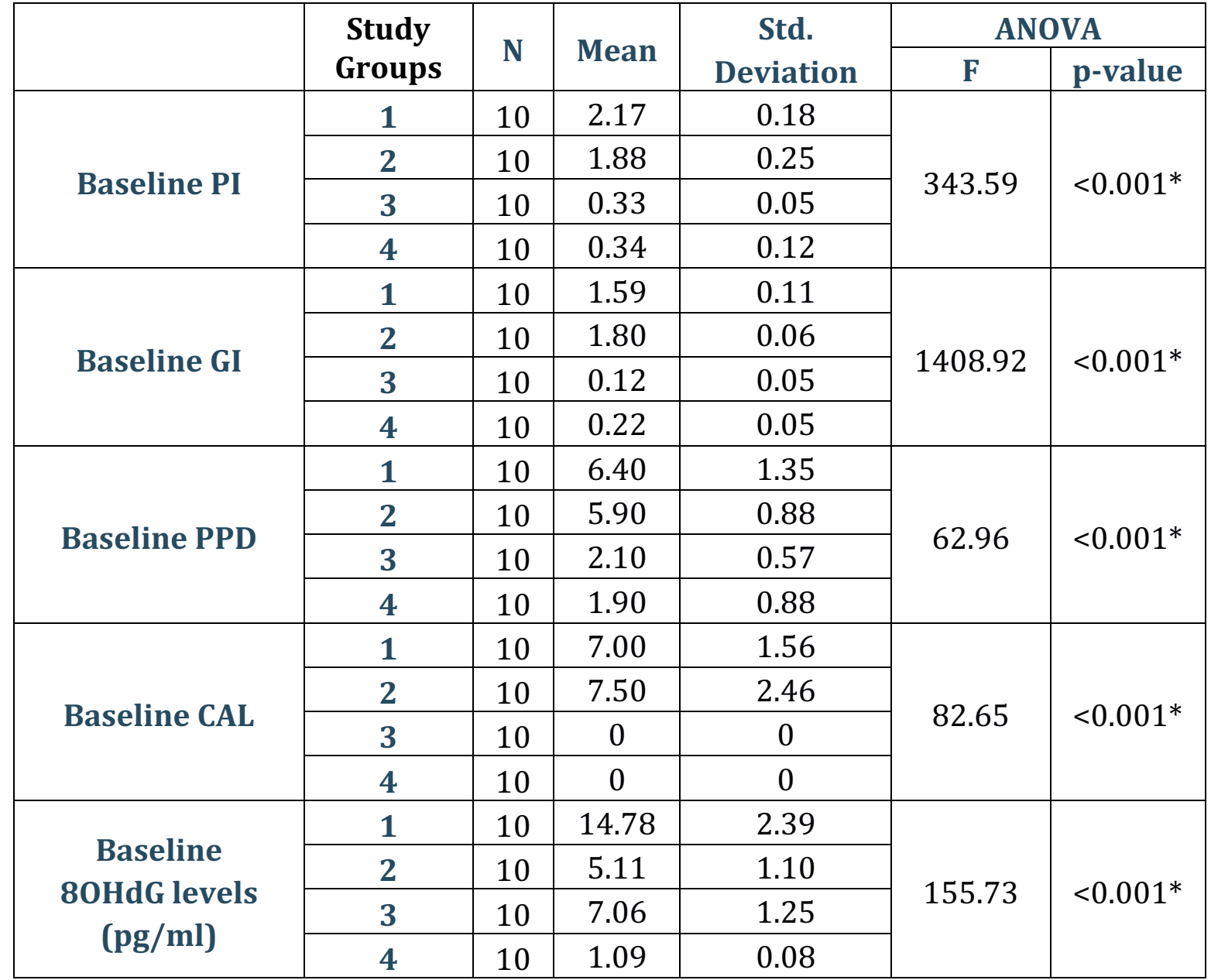

$* p<0.05$ statistically Significant, 
Table 1b

\begin{tabular}{|c|c|c|c|c|c|c|c|}
\hline \multirow[b]{2}{*}{ Dependent Variable } & \multirow{2}{*}{$\begin{array}{l}\text { (I) } \\
\text { Group }\end{array}$} & \multirow{2}{*}{$\begin{array}{l}\text { (J) } \\
\text { Groups }\end{array}$} & \multirow{2}{*}{$\begin{array}{l}\text { Mean } \\
\text { Difference (I-J) }\end{array}$} & \multirow{2}{*}{$\begin{array}{l}\text { Std. } \\
\text { Error }\end{array}$} & \multirow[b]{2}{*}{ p-value } & \multicolumn{2}{|c|}{ 95\% Confidence Interval } \\
\hline & & & & & & $\begin{array}{l}\text { Lower } \\
\text { Bound }\end{array}$ & Upper Bound \\
\hline \multirow{6}{*}{ Baseline PI } & \multirow{3}{*}{1} & 2 & 0.29 & 0.08 & $0.002^{*}$ & 0.09 & 0.49 \\
\hline & & 3 & 1.84 & 0.08 & $<0.001^{*}$ & 1.64 & 2.04 \\
\hline & & 4 & 1.83 & 0.08 & $<0.001^{*}$ & 1.63 & 2.04 \\
\hline & \multirow{2}{*}{2} & 3 & 1.55 & 0.08 & $<0.001^{*}$ & 1.35 & 1.75 \\
\hline & & 4 & 1.54 & 0.08 & $<0.001^{*}$ & 1.34 & 1.74 \\
\hline & 3 & 4 & -0.01 & 0.08 & 0.99 (NS) & -0.21 & 0.19 \\
\hline \multirow{6}{*}{ Baseline GI } & \multirow{3}{*}{1} & 2 & -0.21 & 0.03 & $<0.001^{*}$ & -0.30 & -0.12 \\
\hline & & 3 & 1.47 & 0.03 & $<0.001^{*}$ & 1.38 & 1.55 \\
\hline & & 4 & 1.37 & 0.03 & $<0.001^{*}$ & 1.28 & 1.46 \\
\hline & \multirow{2}{*}{2} & 3 & 1.68 & 0.03 & $<0.001 *$ & 1.59 & 1.77 \\
\hline & & 4 & 1.58 & 0.03 & $<0.001 *$ & 1.49 & 1.67 \\
\hline & 3 & 4 & -0.10 & 0.03 & $0.03 *$ & -0.19 & -0.01 \\
\hline \multirow{6}{*}{ Baseline PPD } & \multirow{3}{*}{1} & 2 & 0.50 & 0.43 & 0.65 (NS) & -0.65 & 1.65 \\
\hline & & 3 & 4.30 & 0.43 & $<0.001 *$ & 3.15 & 5.45 \\
\hline & & 4 & 4.50 & 0.43 & $<0.001^{*}$ & 3.35 & 5.65 \\
\hline & \multirow{2}{*}{2} & 3 & 3.80 & 0.43 & $<0.001^{*}$ & 2.65 & 4.95 \\
\hline & & 4 & 4.00 & 0.43 & $<0.001^{*}$ & 2.85 & 5.15 \\
\hline & 3 & 4 & 0.20 & 0.43 & $0.97(\mathrm{NS})$ & -0.95 & 1.35 \\
\hline \multirow{6}{*}{ Baseline CAL } & \multirow{3}{*}{1} & 2 & -0.50 & 0.65 & $0.87(N S)$ & -2.26 & 1.26 \\
\hline & & 3 & 7.00 & 0.65 & $<0.001 *$ & 5.24 & 8.76 \\
\hline & & 4 & 7.00 & 0.65 & $<0.001 *$ & 5.24 & 8.76 \\
\hline & \multirow{2}{*}{2} & 3 & 7.50 & 0.65 & $<0.001 *$ & 5.74 & 9.26 \\
\hline & & 4 & 7.50 & 0.65 & $<0.001^{*}$ & 5.74 & 9.26 \\
\hline & 3 & 4 & 0.00 & 0.65 & 1.00 (NS) & -1.76 & 1.76 \\
\hline \multirow{3}{*}{$\begin{array}{l}\text { Baseline } 80 \mathrm{HdG} \\
\text { levels }(\mathrm{pg} / \mathrm{mL})\end{array}$} & \multirow{3}{*}{1} & 2 & 9.66 & 0.65 & $<0.001 *$ & 7.91 & 11.41 \\
\hline & & 3 & 7.71 & 0.65 & $<0.001^{*}$ & 5.96 & 9.46 \\
\hline & & 4 & 13.69 & 0.65 & $<0.001^{*}$ & 11.93 & 15.44 \\
\hline
\end{tabular}




\begin{tabular}{|l|l|l|l|l|l|l|l|}
\hline & \multirow{2}{*}{$\mathbf{2}$} & $\mathbf{3}$ & -1.95 & 0.65 & $0.02 *$ & -3.70 & -0.20 \\
\cline { 2 - 8 } & $\mathbf{4}$ & 4.02 & 0.65 & $<0.001^{*}$ & 2.27 & 5.78 \\
\cline { 2 - 8 } & $\mathbf{3}$ & $\mathbf{4}$ & 5.97 & 0.65 & $<0.001^{*}$ & 4.22 & 7.73 \\
\hline
\end{tabular}

Tukey Post Hoc Test

${ }^{*} p<0.05$ statistically Significant,

$p>0.05$ Non Significant, NS

Table 2

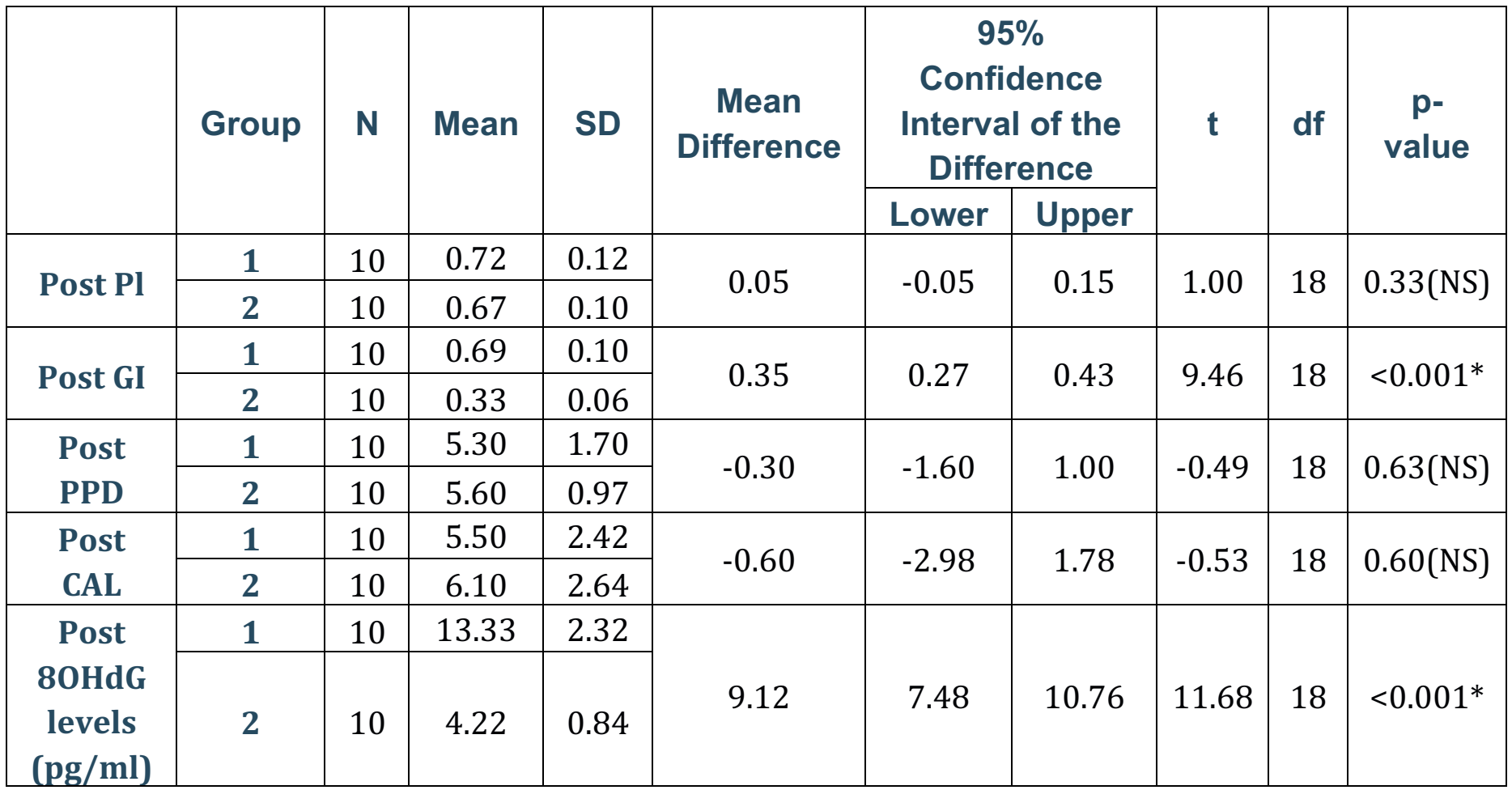

Independent sample $t$ test

${ }^{*} p<0.05$ statistically Significant,

$p>0.05$ Non Significant, NS 
Table 3

\begin{tabular}{|c|c|c|c|c|c|c|c|c|c|c|c|}
\hline \multirow[t]{2}{*}{ Groups } & & & \multirow[t]{2}{*}{$\mathbf{N}$} & \multirow[t]{2}{*}{ Mean } & \multirow[t]{2}{*}{ SD } & \multirow[t]{2}{*}{$\begin{array}{c}\text { Mean } \\
\text { difference }\end{array}$} & \multicolumn{2}{|c|}{$\begin{array}{c}95 \% \\
\text { Confidence } \\
\text { Interval of the } \\
\text { Difference } \\
\end{array}$} & \multirow[t]{2}{*}{$\mathbf{t}$} & \multirow[t]{2}{*}{ df } & \multirow[t]{2}{*}{$\begin{array}{c}p- \\
\text { value }\end{array}$} \\
\hline & & & & & & & Lower & Upper & & & \\
\hline \multirow{10}{*}{1} & \multirow{2}{*}{ PI } & Baseline & 10 & 2.17 & 0.18 & \multirow{2}{*}{1.45} & \multirow{2}{*}{1.32} & \multirow{2}{*}{1.58} & \multirow{2}{*}{25.41} & \multirow{2}{*}{9} & \multirow{2}{*}{$<0.001 *$} \\
\hline & & Post & 10 & 0.72 & 0.12 & & & & & & \\
\hline & \multirow{2}{*}{ GI } & Baseline & 10 & 1.59 & 0.11 & \multirow{2}{*}{0.90} & \multirow{2}{*}{0.78} & \multirow{2}{*}{1.02} & \multirow{2}{*}{16.74} & \multirow{2}{*}{9} & \multirow{2}{*}{$<0.001 *$} \\
\hline & & Post & 10 & 0.69 & 0.10 & & & & & & \\
\hline & \multirow{2}{*}{ PPD } & Baseline & 10 & 6.40 & 1.35 & \multirow{2}{*}{1.10} & \multirow{2}{*}{0.47} & \multirow{2}{*}{1.73} & \multirow{2}{*}{3.97} & \multirow{2}{*}{9} & \multirow{2}{*}{$0.003^{*}$} \\
\hline & & Post & 10 & 5.30 & 1.70 & & & & & & \\
\hline & \multirow{2}{*}{ CAL } & Baseline & 10 & 7.00 & 1.56 & 150 & 053 & 247 & 350 & 9 & $0007 *$ \\
\hline & & Post & 10 & 5.50 & 2.42 & & & & & & \\
\hline & 8OHdG & Baseline & 10 & 14.78 & 2.39 & 144 & 0.68 & 221 & 4.27 & 9 & $0.002 *$ \\
\hline & levels $(\mathrm{pg} / \mathrm{ml})$ & Post & 10 & 13.33 & 2.32 & & & & & & \\
\hline & DI & Baseline & 10 & 1.88 & 0.25 & 121 & 103 & 139 & 1550 & 9 & $<0001 *$ \\
\hline & 11 & Post & 10 & 0.67 & 0.10 & & & & & & 0.001 \\
\hline & CI & Baseline & 10 & 1.80 & 0.06 & 147 & 1.43 & 1.50 & 91.12 & 9 & $<0.001^{*}$ \\
\hline & Ui & Post & 10 & 0.33 & 0.06 & & & & & & \\
\hline & DDD & Baseline & 10 & 5.90 & 0.88 & 030 & -038 & 098 & 100 & 9 & 034 (NS) \\
\hline 2 & H & Post & 10 & 5.60 & 0.97 & & & & & & \\
\hline & CAI & Baseline & 10 & 7.50 & 2.46 & 1.40 & 0.90 & 1.90 & 6.33 & 9 & $<0.001 *$ \\
\hline & ent & Post & 10 & 6.10 & 2.64 & & & & & & \\
\hline & 8OHdG & Baseline & 10 & 5.11 & 1.10 & & & & & & \\
\hline & $\begin{array}{c}\text { levels } \\
\text { (pg/ml) }\end{array}$ & Post & 10 & 4.22 & 0.84 & 0.90 & 0.48 & 1.31 & 4.92 & 9 & $0.001^{*}$ \\
\hline
\end{tabular}

Paired t test

$* p<0.05$ statistically Significant,

$p>0.05$ Non Significant, NS 
Table 4

\begin{tabular}{|c|c|c|c|c|c|c|c|}
\hline & \multirow[b]{2}{*}{ Groups } & \multirow[b]{2}{*}{$\mathbf{N}$} & \multirow[b]{2}{*}{ Mean(SD) } & \multirow[b]{2}{*}{ Range } & \multirow{2}{*}{$\begin{array}{c}\text { Median(Q1- } \\
\text { Q3) }\end{array}$} & \multicolumn{2}{|c|}{ Mann Whitney U test } \\
\hline & & & & & & $\begin{array}{c}\mathrm{U} \\
\text { Statistic }\end{array}$ & p-value \\
\hline \multirow{2}{*}{ PI } & 1 & 10 & $1.45(0.18)$ & $\begin{array}{l}1.20- \\
1.70\end{array}$ & $1.44(1.27-1.62)$ & \multirow{2}{*}{18.5} & \multirow{2}{*}{$0.02 *$} \\
\hline & 2 & 10 & $1.21(0.25)$ & $\begin{array}{c}0.72- \\
1.74 \\
\end{array}$ & $1.21(1.14-1.26)$ & & \\
\hline \multirow{2}{*}{ GI } & 1 & 10 & $0.90(0.17)$ & $\begin{array}{l}0.70- \\
1.22 \\
\end{array}$ & $0.87(0.77-1.07)$ & \multirow{2}{*}{0} & \multirow{2}{*}{$<0.001 *$} \\
\hline & 2 & 10 & $1.47(0.05)$ & $\begin{array}{l}1.42- \\
1.60\end{array}$ & $1.45(1.44-1.48)$ & & \\
\hline \multirow{2}{*}{ PPD } & 1 & 10 & $1.10(0.88)$ & $\begin{array}{l}0.00- \\
3.00\end{array}$ & $1.00(0.75-1.25)$ & \multirow{2}{*}{18.5} & \multirow{2}{*}{$0.008^{*}$} \\
\hline & 2 & 10 & $0.30(0.95)$ & $\begin{array}{l}0.00- \\
3.00\end{array}$ & $0.00(0.00-0.00)$ & & \\
\hline \multirow{2}{*}{ CAL } & 1 & 10 & $1.50(1.35)$ & $\begin{array}{l}0.00- \\
4.00\end{array}$ & $1.00(0.75-3.00)$ & \multirow{2}{*}{46.5} & \multirow{2}{*}{$0.77(\mathrm{NS})$} \\
\hline & 2 & 10 & $1.40(0.70)$ & $\begin{array}{l}1.00- \\
3.00\end{array}$ & $1.00(1.00-2.00)$ & & \\
\hline \multirow{2}{*}{$\begin{array}{c}\text { 8OHdG levels } \\
(\mathrm{pg} / \mathrm{ml})\end{array}$} & 1 & 10 & $1.44(1.07)$ & $\begin{array}{l}0.15- \\
3.67 \\
\end{array}$ & $1.24(0.52-2.04)$ & \multirow{2}{*}{36} & \multirow{2}{*}{$0.29(\mathrm{NS})$} \\
\hline & 2 & 10 & $0.90(0.58)$ & $\begin{array}{l}0.13- \\
2.11 \\
\end{array}$ & $0.87(0.40-1.29)$ & & \\
\hline
\end{tabular}

$* p<0.05$ statistically Significant, $\mathrm{p}>0.05$ Non Significant, NS Mann Whitney U test 
Table 5

\begin{tabular}{|c|c|c|c|c|c|}
\hline \multirow{2}{*}{ Groups } & & & \multicolumn{3}{|c|}{ 80HdG levels (pg/ml) } \\
\hline & & & Baseline $^{\#}$ & Post $^{\#}$ & Change $^{\# \#}$ \\
\hline \multirow{8}{*}{1} & \multirow{2}{*}{ P1 } & Correlation Coefficient & -0.11 & -0.45 & 0.16 \\
\hline & & p-value & $0.77(\mathrm{NS})$ & $0.19(\mathrm{NS})$ & $0.65(\mathrm{NS})$ \\
\hline & \multirow{2}{*}{ GI } & Correlation Coefficient & 0.21 & -0.07 & 0.07 \\
\hline & & p-value & $0.56(\mathrm{NS})$ & $0.85(\mathrm{NS})$ & $0.84(\mathrm{NS})$ \\
\hline & \multirow{2}{*}{ PPD } & Correlation Coefficient & 0.19 & 0.13 & 0.54 \\
\hline & & p-value & $0.59(\mathrm{NS})$ & $0.72(\mathrm{NS})$ & $0.11(\mathrm{NS})$ \\
\hline & \multirow{2}{*}{ CAL } & Correlation Coefficient & -0.45 & -0.27 & 0.04 \\
\hline & & p-value & $0.20(\mathrm{NS})$ & $0.45(\mathrm{NS})$ & $0.92(\mathrm{NS})$ \\
\hline \multirow{8}{*}{2} & \multirow{2}{*}{ P1 } & Correlation Coefficient & -0.22 & 0.12 & 0.00 \\
\hline & & p-value & $0.55(\mathrm{NS})$ & $0.75(\mathrm{NS})$ & $1.00(\mathrm{NS})$ \\
\hline & \multirow{2}{*}{ GI } & Correlation Coefficient & -0.31 & -0.06 & 0.06 \\
\hline & & p-value & $0.39(\mathrm{NS})$ & $0.87(\mathrm{NS})$ & $0.86(\mathrm{NS})$ \\
\hline & \multirow{2}{*}{ PPD } & Correlation Coefficient & 0.21 & 0.63 & -0.17 \\
\hline & & p-value & $0.57(\mathrm{NS})$ & $0.04 *$ & $0.63(\mathrm{NS})$ \\
\hline & \multirow{2}{*}{ CAL } & Correlation Coefficient & -0.001 & -0.07 & 0.05 \\
\hline & & p-value & $1.00(\mathrm{NS})$ & $0.84(\mathrm{NS})$ & $0.90(\mathrm{NS})$ \\
\hline
\end{tabular}

\footnotetext{
\# Pearson's correlation test

\#\# Spearmans correlation test

$* \mathrm{p}<0.05$ statistically significant,

$\mathrm{p}>0.05$ Non significant, NS
} 